\title{
Urticaire et angio-œdème associés à l'infection par le SRAS-CoV-2
}

\author{
Jonathan S. Zipursky MD, David Croitoru MD
}

Citation : CMAJ 2021 September 7;193:E1390. doi : 10.1503/cmaj.211087-f

Voir la version anglaise de l'article ici : www.cmaj.ca/lookup/doi/10.1503/cmaj.211087

$\mathbf{U}$

ne femme de 27 ans a présenté de la fièvre, des céphalées et de la diarrhée. Un test par réaction en chaîne de la polymérase a confirmé une infection par le SRAS-CoV-2. Une semaine plus tard, un érythème urticarien prurigineux migrant est apparu. Elle a consulté au service des urgences où on lui a administré de la prednisone $50 \mathrm{mg}$ et de l'hydroxyzine $10 \mathrm{mg}$, au besoin, avec un certain succès.

Par contre, au cours de la semaine suivante, l'érythème de la patiente s'est aggravé; elle présentait une enflure du visage et des serrements à la poitrine pour lesquels elle a consulté notre service des urgences. Elle n'avait aucun antécédent d'urticaire et n'avait été exposée à aucune nouvelle substance (médicamenteuse, environnementale ou autre). À l'examen, on a noté la présence de plaques érythémateuses (papules) au visage, sur les membres, le torse, à la paume des mains et à la plante des pieds, sans hyperpigmentation postinflammatoire ni purpura (figure 1) et un angio-œdème (œdème de Quincke) affectant les lèvres (annexe 1, accessible en anglais au www.cmaj.ca/lookup/ doi/10.1503/cmaj.211087/tab-related-content). Les urgentologues lui ont administré de l'adrénaline et de la diphénhydramine en raison de son angio-œdème. Nous avons admis la patiente pour la surveiller et nous lui avons prescrit de la cétirizine $20 \mathrm{mg} 2$ fois par jour. Nous avons attribué ses symptômes à une infection aiguë par le SRAS-CoV-2. Elle a reçu son congé hospitalier au bout de 24 heures. Au moment du suivi 12 semaines plus tard, elle présentait encore des crises d'urticaire et prenait de la cétirizine au besoin.

Le diagnostic le plus probable est l'urticaire spontanée chronique déclenchée par le SRAS-CoV-2, mais on a aussi évoqué d'autres possibilités, comme la vascularite urticarienne et l'urticaire chronique inductible. L'urticaire est souvent déclenchée par des infections virales ou bactériennes, dont le virus de l'herpès simplex, le cytomégalovirus, le virus Epstein-Barr, le $\mathrm{VIH}$ et les mycoplasmes ${ }^{1}$. Elle précède ou accompagne souvent les symptômes typiques de la COVID-19, mais s'observe plus rarement une fois les autres symptômes résolus ${ }^{2}$. L'urticaire, les pseudo-engelures et les exanthèmes morbilliformes sont les plus fréquentes manifestations cutanées de la COVID-193. Sa physiopathologie pourrait être due à l'activation du complément et des mastocytes par les effets cytopathologiques directs

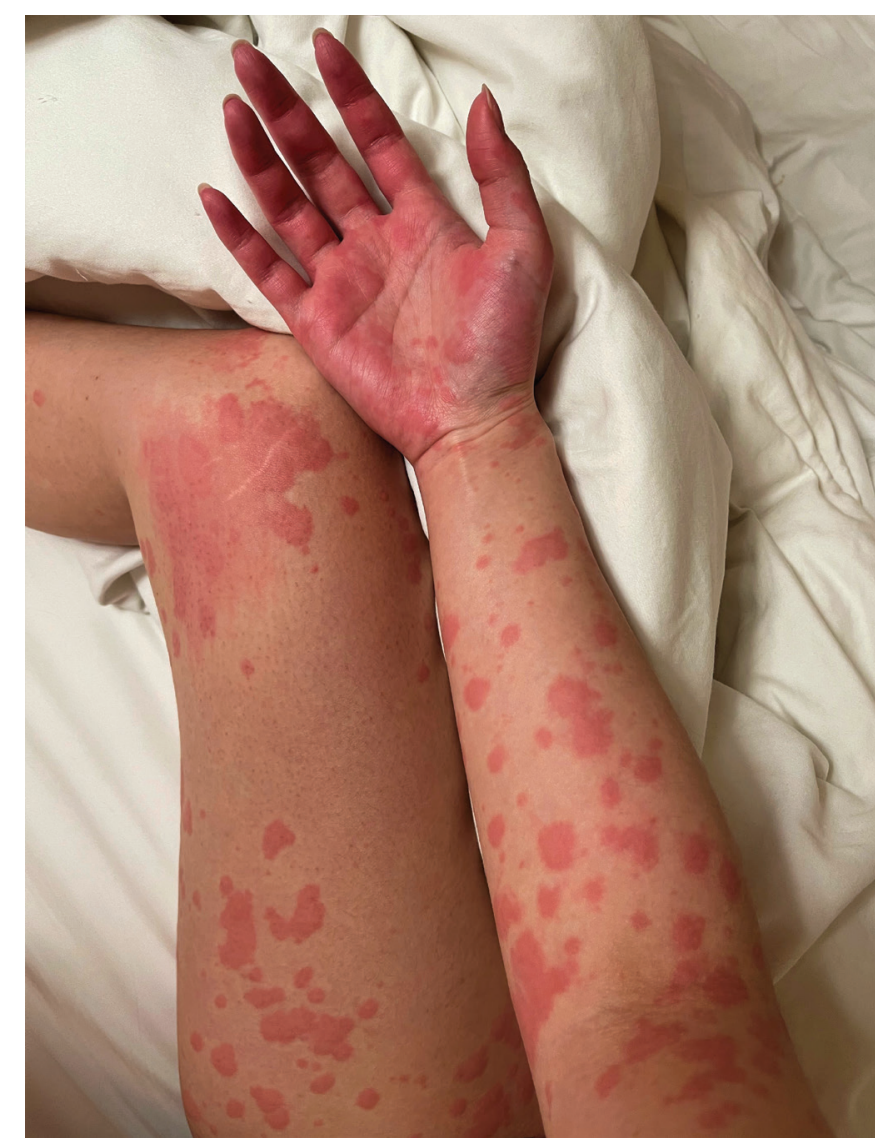

Figure 1 : Plaques érythémateuses surélevées (papules) à la paume des mains, aux bras et aux jambes d'une femme de 27 ans ayant contracté le SRAS-CoV-2.

du SRAS-CoV-2, et aux signaux des cytokines. De plus, la régulation à la baisse de l'enzyme de conversion de l'angiotensine II par le SRASCoV-2, qui entraîne une baisse des taux d'angiotensine II, pourrait exacerber la vasoconstriction ou la perméabilité vasculaire ${ }^{4}$.

Chez les patients qui manifestent un premier épisode d'urticaire ou d'angio-œdème, les médecins devraient faire porter l'interrogatoire sur les symptômes de maladies infectieuses, y compris ceux de la COVID-19. Nous ne suggérons pas un dépistage systématique du SRAS-CoV-2 chez les patients par 
ailleurs asymptomatiques. L'urticaire symptomatique liée au SRAS-CoV-2 devrait être traitée avec des antihistaminiques de seconde et troisième générations non sédatifs à des doses jusqu'à 4 fois supérieures à la dose habituelle, si nécessaire ${ }^{5}$. On peut envisager d'administrer des corticostéroïdes à faible dose par voie systémique dans les cas graves ${ }^{5}$.

\section{Références}

1. Genovese G, Moltrasio C, Berti E, et al. Skin manifestations associated with COVID-19: current knowledge and future perspectives. Dermatology 2021; 237:1-12.

2. Algaadi SA. Urticaria and COVID-19: a review. Dermatol Ther 2020;33:e14290.

3. Freeman EE, McMahon DE, Lipoff JB, et al. The spectrum of COVID-19-associated dermatologic manifestations: an international registry of 716 patients from 31 countries. J Am Acad Dermatol 2020;83:1118-29.

4. Vaduganathan $M$, Vardeny $\mathrm{O}$, Michel $\mathrm{T}$, et al. Renin-angiotensin-aldosterone system inhibitors in patients with COVID-19. N Engl J Med 2020;382:1653-9.

5. Abuelgasim E, Dona ACM, Sondh RS, et al. Management of urticaria in COVID19 patients: a systematic review. Dermatol Ther 2021;34:e14328. doi: 10.1111/ dth. 14328

Intérêts concurrents : Jonathan Zipursky déclare avoir reçu des honoraires pour des opinions médicolégales sur l'innocuité et l'efficacité des médicaments indépendamment des travaux soumis. Aucun autre intérêt concurrent n'a été déclaré.

Cet article a été révisé par des pairs.

Les auteurs ont obtenu le consentement de la patiente.

Affiliations : Département de médecine (Zipursky, Croitoru), Université de Toronto; Département de médecine (Zipursky), Centre des sciences de la santé Sunnybrook; Division de pharmacologie clinique et de toxicologie (Zipursky) et l'Institut des politiques, de la gestion et de l'évaluation de la santé (Zipursky) et Division de dermatologie (Croitoru), Université de Toronto, Toronto, Ont.

Propriété intellectuelle du contenu : Il s'agit d'un article en libre accès distribué conformément aux modalités de la licence Creative Commons Attribution (CC BY-NC-ND 4.0), qui permet l'utilisation, la diffusion et la reproduction de tout médium à la condition que la publication originale soit adéquatement citée, que l'utilisation se fasse à des fins non commerciales (c.-à-d., recherche ou éducation) et qu'aucune modification ni adaptation n'y soit apportée. Voir : https://creativecommons.org/licenses/by-nc-nd/4.0/deed.fr.

Remerciements : Les auteurs remercient Donald Redelmeier pour ses commentaires utiles sur les versions antérieures du manuscrit.

Correspondance : Jonathan Zipursky,

Jonathan.Zipursky@sunnybrook.ca

Les images cliniques sont choisies pour leur caractère particulièrement intéressant, classique ou impressionnant. Toute soumission d'image de haute résolution claire et bien identifiée doit être accompagnée d'une légende aux fins de publication. On demande aussi une brève explication (300 mots maximum) de la portée éducative des images, et des références minimales. Le consentement écrit du patient au regard de la publication doit être obtenu avant la soumission. 